\title{
Neonatal Transcutaneous Carbon Dioxide Monitoring-Effect on Clinical Management and Outcomes
}

\author{
Sagori Mukhopadhyay MD MMSc, Rie Maurer MA, and Karen M Puopolo MD PhD
}

\begin{abstract}
BACKGROUND: This work aimed to compare frequency of blood gas measurements per day of mechanical ventilation, occurrence of extreme blood gas $\mathrm{CO}_{2}$ values, and clinical outcomes among ventilated neonates managed with and without transcutaneous carbon dioxide $\left(\mathbf{P}_{\text {tcCO}_{2}}\right)$ monitors. This work also measures agreement between simultaneous $\mathbf{P}_{\text {tcCO}}$ and blood gas $\mathrm{CO}_{2}$ measurements and ascertains factors that affect agreement. METHODS: This is a cohort study with retrospective analysis comparing 5,726 blood gas measurements and clinical outcomes for 123 neonates intubated for $>48 \mathrm{~h}$ before and after the introduction of transcutaneous carbon-di-oxide monitoring devices in a single tertiary care unit. RESULTS: Median (interquartile range) blood gas frequency per mechanical ventilation day was $3.9(2.6-5.3)$ and $2.9(2.1-4.0)$ before and after $\mathbf{P}_{\text {tcCO}}$ monitoring $(P=.002)$ without differences in clinical outcomes at discharge. After adjusting for confounders using Poisson regression, this difference remained significant. The mean $\pm 2 \mathrm{SD}$ blood gas- $\mathrm{P}_{\mathrm{tccO}}$ difference was $-\mathbf{5 . 2} \pm \mathbf{1 7 . 3} \mathrm{mm} \mathrm{Hg}$. $64 \%$ of simultaneous blood gas- $\mathrm{P}_{\mathrm{tcCO}_{2}}$ measurements per subject were within $\pm 7 \mathrm{~mm} \mathrm{Hg}$. Greater bias was noted with arterial sample and during the use of high-frequency ventilation. CONCLUSION: Despite only moderate agreement between simultaneous $\mathbf{P}_{\mathrm{tcCO}}$ and blood gas measurements, $\mathbf{P}_{\mathrm{tcCO}}$ monitoring statistically decreased blood gas frequency among ventilated neonates without affecting the duration of mechanical ventilation or clinical outcomes at discharge. The clinical impact of this technology appears to be minimal. Key words: capnometry; neonatal; transcutaneous monitoring; outcomes. [Respir Care 2016;61(1):90-97. (c) 2016 Daedalus Enterprises]
\end{abstract}

\section{Introduction}

Infants admitted to the neonatal ICU (NICU) frequently require respiratory support in the form of mechanical ventilation. Arterial, venous and capillary blood gas measure-

\footnotetext{
Drs Mukhopadhyay and Puopolo are affiliated with the Division of Neonatology, Children's Hospital of Philadelphia, Philadelphia, Pennsylvania, the Perelman School of Medicine, University of Pennsylvania, Philadelphia, Pennsylvania, Ms Maurer is affiliated with the Department of Pediatric Newborn Medicine and the Center of Clinical Investigation, Brigham and Women's Hospital, Harvard Medical School, Boston, Massachusetts.

Supplementary material related to this paper is available at http:// www.rcjournal.com.

Dr Mukhopadhyay presented a version of this paper at the Pediatric Academic Society Annual Meeting, held April 25-28, 2015, in San Diego, California.
}

The authors have disclosed no conflicts of interest. ments allow clinicians to gauge the effect of mechanical ventilation on the infant's gas exchange. Samples for blood gas measurement are obtained by invasive techniques resulting in blood loss and only depict the physiologic state of the infant at the point in time when the sample was obtained. ${ }^{1}$ Noninvasive methods to estimate $\mathrm{P}_{\mathrm{CO}_{2}}$ offer a means of continuous assessment of ventilation without accompanying blood loss and infant manipulation. Transcutaneous carbon-dioxide monitors use heated skin sensors that increase blood flow through the cutaneous capillary system. The locally produced $\mathrm{P}_{\mathrm{CO}_{2}}$ is then measured electrochemically and adjusted to provide an output reflective

\footnotetext{
Correspondence: Sagori Mukhopadhyay, The Children's Hospital of Philadelphia, Newborn Care at Pennsylvania Hospital, 800 Spruce Street, 2nd Floor, Cathcart Building, Philadelphia, PA 19107. E-mail: Mukhopadhs@email.chop.edu.
}

DOI: $10.4187 /$ respcare.04212 
of the arterial blood $\mathrm{P}_{\mathrm{CO}_{2}}$. This transcutaneously measure carbon-di-oxide $\left(\mathrm{P}_{\mathrm{tcCO}_{2}}\right)$ has been studied in selected groups of infants for short periods of time, demonstrating good agreement with arterial blood $\mathrm{P}_{\mathrm{CO}_{2}}{ }^{2-6} \mathrm{P}_{\mathrm{tcCO}_{2}}$ monitors are increasingly used in NICUs and are anticipated to improve respiratory and overall care of the neonates. ${ }^{78}$ However, there are reasons to be concerned about the impact of $\mathrm{P}_{\mathrm{tcCO}_{2}}$ monitoring in the course of standard NICU clinical care. Wide agreement between $\mathrm{P}_{\mathrm{tcCO}}$ and arterial blood gas has been reported in the preterm population. ${ }^{2}$ Many NICU infants remain intubated for long duration with evolving physiological states of cardiac output and fluctuating $\mathrm{P}_{\mathrm{CO}_{2}}$ values that may alter $\mathrm{P}_{\mathrm{tcCO}_{2}}$ agreement.9,10 Further, many blood gas samples used in the NICU are capillary samples, and reports to date have correlated $\mathrm{P}_{\mathrm{tcCO}}$ with arterial or venous samples. , $^{, 7,11}$

Although the American Association for Respiratory Care recognized the use of $\mathrm{P}_{\mathrm{tcCO}}$ values in specific clinical situations, their statement noted that a hazard of $\mathrm{P}_{\mathrm{tcCO}_{2}}$ use is "misinterpretation of falsely elevated or decreased values leading to inappropriate treatment of the patient."12 Such false alarms could potentially lead to increased blood draws instead of reducing them or cause unnecessary ventilator manipulation and negatively affect outcomes. There is little published data on these issues. In this study, we aimed to determine whether the use of $\mathrm{P}_{\mathrm{tcCO}}$ monitoring in everyday clinical practice among mechanically ventilated neonates over their entire course of intubation altered respiratory management, specifically blood draws and occurrence of extreme blood gas $\mathrm{P}_{\mathrm{CO}_{2}}$ values, or impacted neonatal morbidities. We also aimed to measure agreement of simultaneously measured $\mathrm{P}_{\mathrm{tcCO}_{2}}$ and blood gas $\mathrm{CO}_{2}$ values and identify factors associated with discordance.

\section{Methods}

\section{Study Population and Design}

This study was approved by the Partners Healthcare Human Research Committee. $\mathrm{P}_{\mathrm{tcCO}_{2}}$ monitors (SenTec AG, Therwil, Switzerland) were introduced for clinical practice to our level III NICU in October 2010. This is a cohort study with retrospective analysis of data spanning 12 months before the introduction of the $\mathrm{P}_{\mathrm{tcCO}}$ monitors, designated pre- $\mathrm{P}_{\mathrm{tcCO}_{2}}$ (October 1, 2009 to September 30, 2010), compared with 14 months following their introduction, designated post- $\mathrm{P}_{\mathrm{tcCO}_{2}}$ (December 1, 2010 to January 31, 2012). October and November of 2010 were considered a washout period (Fig. 1). All infants admitted to the NICU and mechanically ventilated for $>48 \mathrm{~h}$ were included. In the post- $\mathrm{P}_{\mathrm{tcCO}_{2}}$ cohort, inclusion criteria required $\mathrm{P}_{\mathrm{tcCO}_{2}}$ monitor use for $\geq 50 \%$ of the ventilated time because we sought to measure only infants with consistent

\section{QUICK LOOK}

\section{Current knowledge}

$\mathrm{P}_{\mathrm{tcCO}_{2}}$ monitoring uses heated skin sensors that increase blood flow to the cutaneous tissue. The locally produced $\mathrm{P}_{\mathrm{CO}_{2}}$ is then measured electrochemically and adjusted to provide an output reflective of the arterial blood $\mathrm{P}_{\mathrm{CO}_{2}}$. The relationship of $\mathrm{P}_{\mathrm{tcCO}_{2}}$ to $\mathrm{P}_{\mathrm{aCO}}$ is variable, depending on perfusion, temperature, and a number of other variables.

\section{What this paper contributes to our knowledge}

There was a moderate agreement between simultaneous $\mathrm{P}_{\mathrm{tcCO}}$ and $\mathrm{P}_{\mathrm{aCO}}$ measurements. The use of $\mathrm{P}_{\mathrm{tcCO}}$ monitoring statistically decreased blood gas frequency among ventilated neonates without impacting the duration of mechanical ventilation or clinical outcomes.

exposure to the $\mathrm{P}_{\mathrm{tcCO}_{2}}$ monitor during their care. To detect a difference of 1 blood gas/day of mechanical ventilation with a power of 0.8 , we needed at least 52 subjects in each period (PS version 3.1.2). Because we were interested in either an increase or a decrease in blood gas frequency and any increase would be of clinical relevance, this difference was chosen. The post- $\mathrm{P}_{\mathrm{tcCO}}$ period was longer to capture this sample size. Infants with major congenital anomalies as defined by the Vermont Oxford Network or those transferred before extubation were excluded. End-tidal $\mathrm{CO}_{2}$ monitoring was not practiced in the NICU during the study period.

\section{Laboratory and Respiratory Data}

Blood gas analyses were performed on a Siemens (Rapid Lab 1240) analyzer, and results were obtained from an electronic laboratory data repository. $\mathrm{P}_{\mathrm{tcCO}_{2}}$ monitors were applied by respiratory therapists on physician order. Per policy, all ventilated infants were eligible for its use. It was calibrated every $8-12 \mathrm{~h}$, initially with a blood gas drawn 30 min after $\mathrm{P}_{\mathrm{tcCO}_{2}}$ monitor application. Respiratory data were abstracted from the flow sheets where respiratory therapists make date and time stamped entries for $\mathrm{P}_{\mathrm{tcCO}_{2}}$ measurements, simultaneously drawn blood gas results (when performed), and hourly ventilator settings.

\section{Outcome Measurements}

Respiratory outcomes included total blood gas per infant adjusted for mechanical ventilation duration, percentage of extreme blood gas measurements/infant, bias between simultaneous $\mathrm{P}_{\mathrm{tcCO}}$ and blood gas $\mathrm{P}_{\mathrm{CO}_{2}}$ values, and 


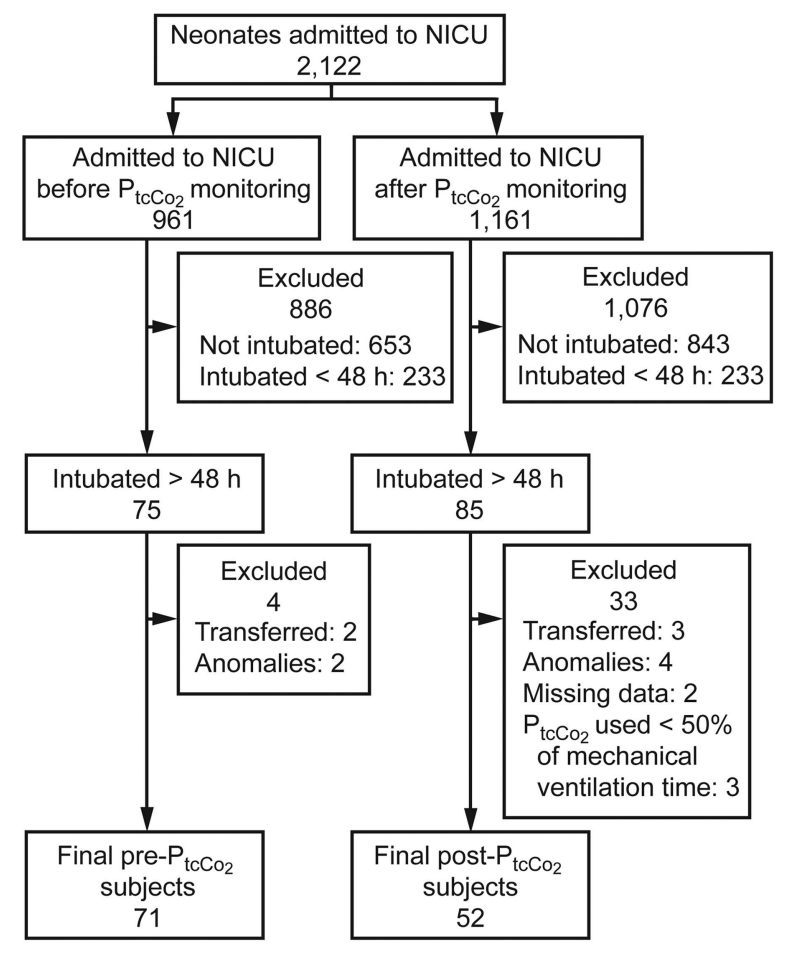

Fig. 1. Flow chart. NICU $=$ neonatal ICU.

bias outside $\pm 7 \mathrm{~mm} \mathrm{Hg}$. Blood gas $\mathrm{P}_{\mathrm{CO}_{2}}$ values of $\leq 35$ and $\geq 70 \mathrm{~mm} \mathrm{Hg}$ were defined as extreme values because values outside of these ranges would generally result in intervention at our institution, irrespective of the infant's $\mathrm{pH}$ or clinical status. Based on previous literature we chose $\pm 7 \mathrm{~mm} \mathrm{Hg}$ as a clinically acceptable bias..$^{5,13-15}$ Clinical outcomes were culture-proven sepsis before (early onset) and after (late onset) 3 days of life; $\geq$ Grade III intraventricular hemorrhage; bronchopulmonary dysplasia, defined as respiratory support or oxygen requirement at 36 weeks gestation (for neonates born $<32$ weeks) or at 28 days of life (for infants $\geq 32$ weeks gestation at birth); necrotizing enterocolitis classified as $\geq$ Bells stage II, including spontaneous intestinal perforation; patent ductus arteriosus diagnosed by echocardiogram or clinically and treated; and type 1 retinopathy of prematurity by ETROP (Early Treatment for Retinopathy of Prematurity) criteria. ${ }^{16}$

\section{Analysis}

Demographic and clinical outcomes of the 2 cohorts were compared using the Fisher exact test, chi-square test, Student $t$ test, and Mann-Whitney test as appropriate. Infants requiring high-frequency ventilation were identified for subgroup analysis a priori. Poisson regression with overdispersion correction and offsetting for duration of mechanical ventilation was used to analyze the effect of $\mathrm{P}_{\mathrm{tcCO}}$ monitor use on blood gas frequency when adjusting for confounders determined on bivariate analysis. We calculated the fraction of extreme values for individual subjects and averaged those values to give us proportions for the entire cohort to account for repeated measurements. After removing $\mathrm{P}_{\mathrm{tcCO}_{2}}$ values of $<15$ or $>100$ as outliers ( $n=23$ observations), we analyzed 1,338 simultaneous $\mathrm{P}_{\mathrm{tcCO}_{2}}$ and blood gas $\mathrm{P}_{\mathrm{CO}_{2}}$ values. Bias was calculated as the $\mathrm{mm} \mathrm{Hg}$ difference between simultaneous $\mathrm{P}_{\mathrm{tcCO}_{2}}$ and blood gas $\mathrm{P}_{\mathrm{CO}_{2}}$ measurements. The agreement between simultaneous $\mathrm{P}_{\mathrm{tcCO}}$ and blood gas $\mathrm{P}_{\mathrm{CO}_{2}}$ values was analyzed using a Bland-Altman plot for repeated measurements per subject with varying true values for each observation, and MedCalc 12.7.5 (MedCalc Software, Ostend, Belgium) was used to generate the plot. To account for repeated measurements in the same subject, we calculated the fraction of values for individual subjects within each bias range $( \pm 5, \pm 7, \pm 10$, and $\pm 15 \mathrm{~mm} \mathrm{Hg}$ ) and averaged those values to give us proportions for the entire cohort. Bivariate analysis of clinical factors associated with a bias outside $\pm 7 \mathrm{~mm} \mathrm{Hg}$ was explored, and a generalized estimating equations model was used to generate an adjusted model. All analysis other than specified was done using SAS 9.3 (SAS Institute, Cary, North Carolina).

\section{Results}

\section{Frequency and Range of Blood Gas Measurements}

Derivation of the study population is outlined in Figure 1. There were no significant differences in the admission characteristics and initial management between the 2 cohorts (Table 1). Median blood gas frequency per day of mechanical ventilation per infant was significantly lower in the post $-\mathrm{P}_{\mathrm{tcCO}}$ period. The decrease in blood gas frequency was greater among the subset of infants who required high-frequency ventilation (jet or oscillatory ventilation) at any time (Table 2). Birthweight, gestational age, low admission temperature $<36^{\circ} \mathrm{C}$, use of $\mathrm{P}_{\mathrm{tcCO}}$ monitoring, and high-frequency ventilation were significantly related to total number of blood gases for a subject in the bivariate analysis using Poisson regression when offsetting for duration of mechanical ventilation. In the multivariate model, adjusting for these variables and offsetting for mechanical ventilation duration, use of $\mathrm{P}_{\mathrm{tcCO}}$ monitors remained significantly associated with reduced blood gases along with the use of high-frequency ventilation (Table 3 ). The post- $\mathrm{P}_{\mathrm{tcCO}_{2}}$ cohort on average had a lower percentage of extreme values at $17.8 \pm 8.4 \%$ than the pre- $\mathrm{P}_{\mathrm{tcCO}_{2}}$ cohort with $19.4 \pm 8.7 \%$, but this difference was not significant (Table 2).

\section{Clinical Outcomes}

There were no significant differences in the duration of mechanical ventilation or use of rescue high-frequency 
Table 1. Clinical Characteristics of Infants in the Pre- $\mathrm{P}_{\mathrm{tcCO}}$ and Post- $\mathrm{P}_{\mathrm{tcCO}_{2}}$ Periods

\begin{tabular}{|c|c|c|c|}
\hline & Pre- $\mathrm{P}_{\mathrm{tcCO}_{2}}(n=71)$ & Post- $\mathrm{P}_{\mathrm{tcCO}_{2}}(n=52)$ & $P$ \\
\hline Female, $n(\%)$ & $37(52.1)$ & $25(48.1)$ & .72 \\
\hline Gestational weeks at birth, mean $\pm \mathrm{SD}$ & $28.6 \pm 4.3$ & $27.7 \pm 3.9$ & .24 \\
\hline Birth gestation $<37$ weeks, $n(\%)$ & $67(94.4)$ & $49(94.2)$ & $>.99$ \\
\hline Birth weight, mean $\pm \mathrm{SD} g$ & $1,228 \pm 854$ & $1,062 \pm 730$ & .26 \\
\hline Birth weight $<1,500 \mathrm{~g}, n(\%)$ & $56(78.9)$ & $46(88.5)$ & .23 \\
\hline Race, $n(\%)$ & & & .22 \\
\hline White & $42(59.2)$ & $25(48.1)$ & \\
\hline Black & $14(19.7)$ & $14(26.9)$ & \\
\hline Hispanic & $13(18.3)$ & $8(15.4)$ & \\
\hline Others & $2(2.8)$ & $5(9.62)$ & \\
\hline Steroid-eligible, $n(\%)$ & $60(84.5)$ & $48(92.3)$ & .27 \\
\hline Received any dose, $n(\%)$ & $57(95)$ & $44(91.7)$ & .70 \\
\hline Multiple gestation, $n(\%)$ & $20(28.2)$ & $24(46.2)$ & .057 \\
\hline C-section, $n(\%)$ & $55(77.5)$ & $42(80.8)$ & .82 \\
\hline Apgar score $<5$ at $5 \mathrm{~min}, n(\%)$ & $7(9.9)$ & $6(11.5)$ & 67 \\
\hline Admission temperature, mean $\pm \mathrm{SD}{ }^{\circ} \mathrm{C}$ & $36.3 \pm 0.7$ & $36.5 \pm 0.4$ & .12 \\
\hline Ionotroph use during mechanical ventilation, $n(\%)$ & $36(50.7)$ & $23(44.2)$ & .58 \\
\hline Surfactant use, $n(\%)$ & $70(98.6)$ & $52(100)$ & $>.99$ \\
\hline Arterial line at any time during mechanical ventilation, $n(\%)$ & $55(77.5)$ & $42(80.8)$ & .82 \\
\hline Indication for intubation, $n(\%)$ & & & .82 \\
\hline RDS & $51(71.8)$ & $41(78.9)$ & \\
\hline Neurologic abnormality & $2(2.8)$ & $1(1.9)$ & \\
\hline MAS and/or PPHN & $2(2.8)$ & $2(3.9)$ & \\
\hline Evolving lung disease* & $10(14.1)$ & $6(11.5)$ & \\
\hline Others $\dagger$ & $6(8.5)$ & $2(3.8)$ & \\
\hline
\end{tabular}

\footnotetext{
* Evolving lung disease was defined as infants who were intubated or re-intubated after the first $3 \mathrm{~d}$ of life. Respiratory distress syndrome was defined as diagnosed in the medical record with intubation within the first $3 \mathrm{~d}$ of life.

$\dagger$ Others included airway issues, culture-positive sepsis, or necrotizing enterocolitis stage $\geq 2$.

RDS $=$ respiratory distress syndrome

MAS $=$ meconium aspiration syndrome

$\mathrm{PPHN}=$ persistent pulmonary hypertension
}

ventilation in the 2 cohorts. The clinical outcomes measured at the time for hospital discharge between the 2 cohorts were also not significantly different (Table 2).

\section{Blood Gas $\mathbf{P}_{\mathrm{CO}_{2}}$ and $\mathbf{P}_{\mathrm{tcCO}}$ Measure Agreement}

We analyzed 1,338 simultaneous $\mathrm{P}_{\mathrm{tcCO}_{2}}$ and blood gas measurements from 52 subjects in the post- $\mathrm{P}_{\text {tcCO }}$ cohort. Using a Bland-Altman plot for multiple measurements, we found mean $\pm 2 \mathrm{SD}$ bias of $-5.2 \pm 17.3$ (Fig. 2). Subgroup analysis using only arterial blood gas values included 774 paired samples and found a mean bias \pm 2 SD of $-7.2 \pm 16$. An average of $51.4 \pm 21.5 \%$ of paired measurements had bias within $\pm 5 \mathrm{~mm} \mathrm{Hg} ; 64 \pm 20.6 \%$ within $\pm 7 \mathrm{~mm} \mathrm{Hg} ; 78 \pm 17.6 \%$ within $\pm 10 \mathrm{~mm} \mathrm{Hg}$; and $92 \pm 10.3 \%$ within $\pm 15 \mathrm{~mm} \mathrm{Hg}$. On bivariate analysis, increasing birthweight, increasing blood gas measurements, high-frequency ventilation at the time of blood gas measure, and arterial sample were significant predictors of a bias outside $\pm 7 \mathrm{~mm} \mathrm{Hg}$ (Table 4 ). In the multivariable model, when adjusting for birthweight and blood gas number, being on high-frequency ventilation at the time of the blood gas measurement and having an arterial sample continued to significantly increase the odds of a bias $\pm 7 \mathrm{~mm} \mathrm{Hg}$ (Table 4). There was no significant relationship of sex, gestational age at birth, or chronological age of the infant at the time of the blood gas measurement.

\section{Excluded Population}

Of the 76 eligible infants in the post- $\mathrm{P}_{\mathrm{tcCO}}$ period, 24 were excluded, per study criteria, due to $<50 \%$ use of $\mathrm{P}_{\mathrm{tcCO}_{2}}$ monitoring for the duration of mechanical ventilation. To account for selection bias, we compared the demographics and clinical characteristics of neonates excluded with those of neonates included and found that $\mathrm{P}_{\mathrm{tcCO}_{2}}$ monitor use $<50 \%$ of mechanical ventilation time was associated with shorter median mechanical ventilation time (5.4 [interquartile range 3.7-14.3] days vs 8.7 [interquartile range 5.6-22.1] days, $P=.027)$, lower surfactant 
Table 2. Neonatal Blood Gas Comparison and Clinical Outcome of the 2 Cohorts $(N=123$; Blood Gas Measurements $=5,726)$

\begin{tabular}{|c|c|c|c|}
\hline & Pre- $\mathrm{P}_{\mathrm{tcCO}_{2}}(n=71)$ & Post- $\mathrm{P}_{\mathrm{tcCO}_{2}}(n=52)$ & $P$ \\
\hline Mechanical ventilation, median (IQR) d & $7.8(4.1-33.3)$ & $8.7(5.6-22)$ & .57 \\
\hline Use of any HFV, $n(\%)$ & $32(45.1)$ & $29(55.8)$ & .28 \\
\hline HFV, median (IQR) d & $4.3(2.4-7.8)$ & $3.5(3-7)$ & .66 \\
\hline BGs drawn/d of mechanical ventilation, median (IQR) & $3.9(2.6-5.3)$ & $2.9(2.1-4.0)$ & .002 \\
\hline BGs drawn/d of HFV, median (IQR) & $6.6(5.5-8)$ & $4.7(3.3-5.2)$ & $<.001$ \\
\hline$\%$ of $\mathrm{BG} \mathrm{P}_{\mathrm{CO}_{2}}$ values outside $35-70 \mathrm{~mm} \mathrm{Hg}$ range, mean $\pm \mathrm{SD}$ & $19.4 \pm 8.7$ & $17.8 \pm 8.4$ & .48 \\
\hline$\%$ of arterial $\mathrm{BG} /$ patient, mean $\pm \mathrm{SD}$ & $62.6 \pm 33.8$ & $64.9 \pm 28.8$ & .71 \\
\hline$\%$ of capillary BG/patient, mean $\pm \mathrm{SD}$ & $47.1 \pm 31.5$ & $45.7 \pm 31.8$ & .82 \\
\hline$\%$ of venous $\mathrm{BG} /$ patient, mean $\pm \mathrm{SD}$ & $7.7 \pm 13.3$ & $5.1 \pm 3.0$ & .45 \\
\hline Postnatal steroid use, $n(\%)$ & $3(4.2)$ & $1(1.9)$ & .64 \\
\hline Bronchopulmonary dysplasia, $n(\%)$ & $25(35.2)$ & $24(46.2)$ & .27 \\
\hline Retinopathy of prematurity, $n(\%)$ & $5(7)$ & $3(5.8)$ & .66 \\
\hline Necrotizing enterocolitis, $n(\%)$ & $10(14.1)$ & $5(9.6)$ & .58 \\
\hline Surgical necrotizing enterocolitis, $n(\%)$ & $6(8.5)$ & $3(5.8)$ & $>.99$ \\
\hline Intraventricular hemorrhage, $n(\%)$ & $15(21.1)$ & $14(26.9)$ & .52 \\
\hline Patent ductus arteriosus, $n(\%)$ & $53(74.7)$ & $42(80.7)$ & .52 \\
\hline Early onset sepsis, $n(\%)$ & $2(2.8)$ & $1(1.9)$ & $>.99$ \\
\hline Late onset sepsis, $n(\%)$ & $12(16.9)$ & $6(11.5)$ & .37 \\
\hline Failed hearing screen, $n(\%)$ & $5(7.0)$ & $2(3.9)$ & .38 \\
\hline No. of blood transfusions, mean \pm SD & $6.1 \pm 5.4$ & $5.8 \pm 3.8$ & .68 \\
\hline Disposition, $n(\%)$ & & & .43 \\
\hline Home & $52(73.2)$ & $42(80.8)$ & \\
\hline Died & $9(12.7)$ & $3(5.8)$ & \\
\hline Transferred & $10(14.1)$ & $7(13.5)$ & \\
\hline Mortality, $n(\%)$ & $9(12.7)$ & $3(5.8)$ & .24 \\
\hline Median d of hospital stay (IQR)* & $89(49-107)$ & $95(81-105)$ & .21 \\
\hline $\begin{array}{l}\text { * Reported for neonates going home. } \\
\mathrm{IQR}=\text { interquartile range } \\
\mathrm{HFV}=\text { high-frequency ventilation } \\
\mathrm{BG}=\text { blood gas }\end{array}$ & & & \\
\hline
\end{tabular}

use $(87.5 \%$ vs $100 \%, P=.028)$ and high-frequency ventilation use $(16.7 \%$ vs $55.8 \%, P=.002)$, suggesting a healthier group. Other clinical characteristics were comparable (see Supplementary Table 1 at http://www.rcjournal.com).

\section{Discussion}

In this study, we found that use of $\mathrm{P}_{\mathrm{tcCO}}$ monitors in the NICU did not increase and in fact reduced the frequency of blood gas sampling despite only moderate agreement (Tables 2 and 3). $\mathrm{P}_{\text {tcCO}}$ monitor use could have had no impact on the frequency of blood gas sampling if clinicians did not trust the $\mathrm{P}_{\mathrm{tcCO}_{2}}$ output; conversely, the continuous display of (potentially abnormal) $\mathrm{P}_{\mathrm{tcCO}_{2}}$ output could have prompted more sampling if clinicians felt obliged to obtain confirmatory blood gases. However, we found that among the infants for whom $\mathrm{P}_{\mathrm{tcCO}_{2}}$ monitoring was used $\geq 50 \%$ of the mechanical ventilation time, the addition of $\mathrm{P}_{\text {tcCO}}$ monitoring technology reduced blood gases. This finding was robust when controlling for de- mographic characteristics and markers of severity of respiratory illness over 2 time periods and within the subgroup of infants requiring high-frequency ventilation (Tables 2 and 3). The clinical impact of this reduction in terms of blood loss is possibly minor, and the absence of a larger difference is possibly related to the wide agreement. We found no difference in frequency of arterial line insertion, type of arterial line (umbilical vs peripheral), or blood transfusions in the 2 cohorts (Tables 1 and 2). Transcutaneous devices, which reduce the need for needle sticks, have been cited as a mode for decreasing pain in the care of newborns. ${ }^{17}$ In the current study, we were unable to obtain frequency of needle sticks in the cohorts. The impact of reduced blood gas frequency on acute and chronic pain scores when considering manipulation needed to apply $\mathrm{P}_{\mathrm{tcCO}_{2}}$ monitors remains to be explored.

The availability of a continuous display of $\mathrm{CO}_{2}$ levels could have hastened corrective changes to ventilator parameters before the values drifted to extreme levels. However, the percentage of extreme values in the 2 cohorts was not significantly different. Using blood gas $\mathrm{P}_{\mathrm{CO}_{2}}$ as a marker 
Table 3. Incidence Rate Ratios for Total Number of Gases by Bivariate and Multivariate Poisson Regression When Offsetting for Duration of Mechanical Ventilation

\begin{tabular}{|c|c|c|c|c|}
\hline Predictor & Bivariate IRR $(95 \% \mathrm{CI})$ & $P$ & Adjusted IRR (95\% CI) & $P$ \\
\hline Gestational age, wks & $1.04(1.01-1.06)$ & .003 & $1.02(0.97-1.07)$ & .41 \\
\hline Birth weight, $g$ & $1.00(1.00-1.00)$ & .001 & $1.00(0.99-1.00)$ & .34 \\
\hline $\mathrm{P}_{\mathrm{tcCO}_{2}}$ monitor used & $0.82(0.69-0.97)$ & .02 & $0.80(0.7-0.93)$ & .003 \\
\hline Use of any HFV & $1.56(1.34-1.82)$ & $<.001$ & $1.59(1.38-1.82)$ & $<.001$ \\
\hline Admission temperature $<36^{\circ} \mathrm{C}$ & $1.24(1.03-1.49)$ & .02 & $0.88(0.76-1.03)$ & .11 \\
\hline Male sex & $1.10(0.93-1.29)$ & .28 & NA & NA \\
\hline White race & $1.00(0.85-1.18)$ & .98 & NA & NA \\
\hline Vaginal delivery & $0.97(0.79-1.19)$ & .74 & NA & NA \\
\hline No antenatal steroids & $1.15(0.97-1.38)$ & .11 & NA & NA \\
\hline Multiple gestation & $0.85(0.71-1.02)$ & .08 & NA & NA \\
\hline Apgar score $\geq 5$ at $5 \mathrm{~min}$ & $0.81(0.64-1.03)$ & .08 & NA & NA \\
\hline No inotrope use & $0.90(0.76-1.07)$ & .24 & NA & NA \\
\hline $\begin{array}{l}\mathrm{IRR}=\text { incidence rate ratio } \\
\mathrm{HFV}=\text { high frequency ventilation } \\
\mathrm{NA}=\text { not applicable }\end{array}$ & & & & \\
\hline
\end{tabular}

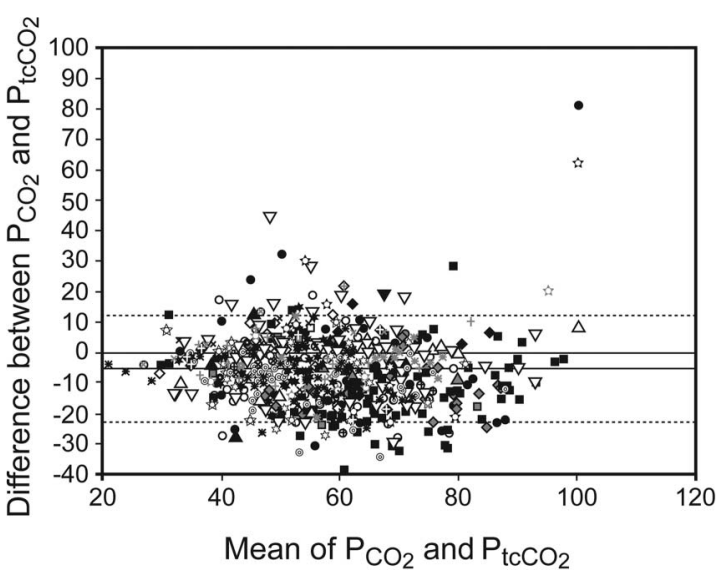

Fig. 2. Bland-Altman plot for multiple measurements of 52 subjects with 1,338 simultaneous blood gas $-\mathrm{P}_{\mathrm{tcCO}}$ measurements. Multiple measurements for each subjects are depicted by a unique shape. The center horizontal line depicts the mean, and outside dotted lines show \pm SD.

of $\mathrm{P}_{\mathrm{CO}_{2}}$ fluctuations is biased by the fact that blood gas $\mathrm{P}_{\mathrm{CO}_{2}}$ values in the abnormal range trigger more blood gases, whereas the absence of out-of-range values in another subject may merely reflect fewer tests. We partly adjusted for this by dividing the number of extreme values by the total blood gas number per infant. Our small sample size may also be insufficient to detect a statistically significant difference. Prospective timed sampling of infants with and without $\mathrm{P}_{\mathrm{tcCO}}$ monitoring would be needed to demonstrate variability with more precision.

Our study demonstrates that $\mathrm{P}_{\mathrm{tcCO}_{2}}$ monitoring is a reliable source of clinical information in most, but not all, critically ill neonates. $64 \%$ of values had a bias within $\pm 7 \mathrm{~mm} \mathrm{Hg}$. We also found wider agreement limits of 12.2 to -22.5 compared with some prior studies. ${ }^{4,5,13,14}$
Our study, however, evaluates a large blood gas- $\mathrm{P}_{\mathrm{tcCO}}$ sample over the entire span of an infant's ventilated course, making fluctuation in agreement more likely. Further, $>80 \%$ of our population is constituted by very low birthweight infants, in whom a lower correlation has been reported, compared with pediatric and adult studies. ${ }^{2}$ Of note, it is likely that despite the moderate agreement, the reduction in blood gas frequency was due to the use of the $\mathrm{P}_{\mathrm{tcCO}_{2}}$ values as a trend rather than as a point in time measure.

We investigated variables associated with wide blood gas- $\mathrm{P}_{\mathrm{tcCO}}$ agreement. Most studies previously reporting agreement have used arterial blood gases, which is the accepted standard. ${ }^{2,4,14}$ Recently, good correlation was also reported between $\mathrm{P}_{\mathrm{tcCO}_{2}}$ measurements and venous samples among pediatric subjects. ${ }^{11}$ In our study, $41 \%$ of simultaneous $\mathrm{P}_{\mathrm{tcCO}_{2}}$ and blood gas values were capillary samples. A survey of 39 NICUs in Europe reported that $49 \%$ of units used capillary gases to calibrate $\mathrm{P}_{\mathrm{tcCO}}$ measurements. ${ }^{7}$ There is no information on the agreement of $\mathrm{P}_{\mathrm{tcCO}_{2}}$ with capillary gases, which, although not the accepted standard, are frequently used in practice. We found that $\mathrm{P}_{\mathrm{tcCO}}$ values agree better with capillary blood samples than arterial (Table 4). This is perhaps not surprising, given that the $\mathrm{P}_{\mathrm{tcCO}_{2}}$ monitor senses $\mathrm{CO}_{2}$ diffusion from heated capillary beds and possibly conveys the same difference that capillary gases demonstrate from simultaneous arterial gases. We adjusted for the infant's age (because arterial samples are likely to be obtained earlier in the infant's care when umbilical arterial lines are present and respiratory status is evolving) and mode of ventilation. Arterial blood gases remained associated with greater bias than capillary samples. We also found significant associations with the use of high-frequency ventilation and bias 
Table 4. Adjusted Odds Ratios for Factors Contributing to Blood Gas- $\mathrm{P}_{\mathrm{tcCO}}$ Bias Greater Than $\pm 7 \mathrm{~mm} \mathrm{Hg}$

\begin{tabular}{lccr}
\hline \hline \multicolumn{1}{c}{ Predictor } & Bivariate Odds Ratio (95\% CI) & $P$ & Adjusted Odds Ratio (95\% CI) \\
\hline Gestational age (per wk) & $1.03(0.97-1.08)$ & .27 & NA \\
Male sex & $0.96(0.62-1.48)$ & .84 & NA \\
Infant age at the time of the BG (per d) & $0.98(0.95-1.02)$ & .34 & NA \\
Birth weight (per 100 g) & $1.03(1-1.05)$ & .02 & $1.02(0.99-1.05)$ \\
HFV at the time of the BG & $1.83(1.3-2.6)$ & $<.001$ & $1.56(1.06-2.27)$ \\
Arterial sample & $1.75(1.27-2.44)$ & $<.001$ & $1.67(1.22-2.28)$ \\
No. of total BG (per 5 BG) & $1.04(1.01-1.07)$ & .003 & $1.05(1.02-1.08)$ \\
& & & .02 \\
NA = not applicable & & & .001 \\
BG = blood gas & & & .001 \\
HFV = high frequency ventilation & & \\
\hline
\end{tabular}

greater than \pm 7 (Table 4). High-frequency ventilation is largely used as a rescue mode of ventilation in our center, and therefore blood $\mathrm{P}_{\mathrm{CO}_{2}}$ levels tend to be higher before high-frequency ventilation is initiated, which can cause wider agreement limits. Sicker infants on high-frequency ventilation possibly have differences in peripheral perfusion that we could not quantify in this study.

Finally, we addressed the impact of $\mathrm{P}_{\text {tcCO}}$ monitoring on infant outcomes. More frequent ventilator changes could impact infants in a positive manner by better control of $\mathrm{CO}_{2}$ or could simply lead to more interventions for inaccurate reads that negatively impacted outcomes. We found no difference in major clinical or respiratory outcomes (Table 2). Our findings are, however, limited by our sample size, which was not powered for the individual clinical outcomes. A prospective, randomized, and blinded study of infants clinically managed with and without $\mathrm{P}_{\mathrm{tcCO}_{2}}$ monitoring would be needed to accurately assess whether the use of $\mathrm{P}_{\text {tcCO}}$ monitors influences ventilator control and clinical outcomes in neonates.

Our study is limited by its retrospective, observational design based on a single center experience. We focused on sick NICU infants requiring mechanical ventilation for $>48 \mathrm{~h}$, including a heterogeneous array of pathologies ranging from extreme prematurity to meconium aspiration in term infants. We selected this group to reflect a NICU population where the use of a $\mathrm{P}_{\mathrm{tcCO}_{2}}$ monitor could have most impact. Our results are therefore best generalizable to this population. We excluded 24 infants in the post- $\mathrm{P}_{\mathrm{tcCO}}$ period because they spent $<50 \%$ of their mechanical ventilation time on $\mathrm{P}_{\mathrm{tcCO}}$ monitors. This exclusion criterion was designed a priori to limit inclusion of infants where $\mathrm{P}_{\text {tcCO}}$ monitor use was insufficient to have a conceivable impact. We found no significant demographic differences when we compared these infants with those who did have $\mathrm{P}_{\text {tcCO}}$ monitor use $\geq 50 \%$ of the ventilated time, although significantly reduced surfactant need, mechanical ventilation duration, and high-frequency ventilation use suggest that the infants with $<50 \%$ of ventilated time on $\mathrm{P}_{\mathrm{tcCO}_{2}}$ monitors were less severely ill (see Supplementary Table 1 ). We could not completely ascertain why these infants spent $<50 \%$ of ventilated time on $\mathrm{P}_{\mathrm{tcCO}_{2}}$ monitors. Chart review suggests that in some cases, an initial lack of correlation led to early abandonment of the technology; in others, rapid clinical improvement may have led to the idea that it was not needed; but in many cases no reason could be determined. This exclusion criterion was designed to reflect real-life practice, and we recognize that it probably selected for infants in whom care providers identified $\mathrm{P}_{\mathrm{tcCO}}$ monitors to correlate better. The pre-post cohort design limits our ability to account for secular trends. Although this limitation cannot be resolved completely, the proximity of the time periods studied, absence of any major NICU respiratory management policy changes during the time, and comparable demographics of the infants minimize the impact of this limitation on the results of the study.

\section{Conclusions}

$\mathrm{P}_{\mathrm{tcCO}_{2}}$ monitoring is used in clinical practice with moderate correlation in most neonates over a range of gestational ages, disease pathology, and modes of ventilation. In clinical practice, when used consistently, $\mathrm{P}_{\mathrm{tcCO}_{2}}$ monitors were associated with decreased blood gas sampling but no significant change in ventilatory control or major morbidities. Further study is needed to determine how to optimally employ this noninvasive monitoring technique, potentially to decrease phlebotomy-associated blood loss and increase the safety of mechanical ventilation.

\section{REFERENCES}

1. Widness JA, Madan A, Grindeanu LA, Zimmerman MB, Wong DK, Stevenson DK. Reduction in red blood cell transfusions among preterm infants: Results of a randomized trial with an in-line blood gas and chemistry monitor. Pediatrics 2005;115(5):1299-306.

2. Aliwalas LL, Noble L, Nesbitt K, Fallah S, Shah V, Shah PS. Agreement of carbon dioxide levels measured by arterial, transcutaneous 


\section{Neonatal Transcutaneous Carbon Dioxide Monitoring}

and end tidal methods in preterm infants $<$ or $=28$ weeks gestation. J Perinatol 2005;25(1):26-29.

3. Berkenbosch JW, Tobias JD. Transcutaneous carbon dioxide monitoring during high-frequency oscillatory ventilation in infants and children. Crit Care Med 2002;30(5):1024-1027.

4. Sandberg KL, Brynjarsson H, Hjalmarson O. Transcutaneous blood gas monitoring during neonatal intensive care. Acta Paediatr 2011; 100(5):676-679.

5. Tingay DG, Stewart MJ, Morley CJ. Monitoring of end tidal carbon dioxide and transcutaneous carbon dioxide during neonatal transport. Arch Dis Child Fetal Neonatal Ed. 2005;90(6):F523-F526.

6. Bernet V, Döll C, Cannizzaro V, Ersch J, Frey B, Weiss M. Longtime performance and reliability of two different $\mathrm{PtcCO}_{2}$ and $\mathrm{SpO}_{2}$ sensors in neonates. Paediatr Anaesth 2008;18(9):872-877.

7. Rüdiger M, Töpfer K, Hammer H, Schmalisch G, Wauer RR. A survey of transcutaneous blood gas monitoring among european neonatal intensive care units. BMC Pediatr 2005;5:30.

8. Urbano J, Cruzado V, López-Herce J, del Castillo J, Bellón JM, Carrillo A. Accuracy of three transcutaneous carbon dioxide monitors in critically ill children. Pediatr Pulmonol 2010;45(5):481-486.

9. Cassady G. Transcutaneous monitoring in the newborn infant. J Pediatr 1983;103(6):837-848.

10. Hejlesen OK, Cichosz SL, Vangsgaard S, Andresen MF, Madsen LP. Clinical implications of a quality assessment of transcutaneous $\mathrm{CO}_{2}$ monitoring in preterm infants in neonatal intensive care. Stud Health Technol Inform 2009;150:490-494.
11. Gal S, Riskin A, Chistyakov I, Shifman N, Srugo I, Kugelman A. Transcutaneous $\mathrm{PCO}_{2}$ monitoring in infants hospitalized with viral bronchiolitis. Eur J Pediatr. 2015;174(3):319-324.

12. Restrepo RD, Hirst KR, Wittnebel L, Wettstein R. AARC clinical practice guideline: Transcutaneous monitoring of carbon dioxide and oxygen: 2012. Respir Care 2012;57(11):1955-1962.

13. Tingay DG, Mun KS, Perkins EJ. End tidal carbon dioxide is as reliable as transcutaneous monitoring in ventilated postsurgical neonates. Arch Dis Child Fetal Neonatal Ed. 2013;98(2):F161F164.

14. Storre JH, Magnet FS, Dreher M, Windisch W. Transcutaneous monitoring as a replacement for arterial $\mathrm{PCO}_{2}$ monitoring during nocturnal non-invasive ventilation. Respir Med 2011;105(1):143-150.

15. Cox M, Kemp R, Anwar S, Athey V, Aung T, Moloney ED. Noninvasive monitoring of $\mathrm{CO}_{2}$ levels in patients using NIV for AECOPD. Thorax 2006;61(4):363-364.

16. Early Treatment For Retinopathy Of Prematurity Cooperative Group. Revised indications for the treatment of retinopathy of prematurity: results of the early treatment for retinopathy of prematurity randomized trial. Arch Ophthalmol. 2003;121(12):1684-1694.

17. American Academy of Pediatrics Committee on Fetus and Newborn, American Academy of Pediatrics Section on Surgery, Canadian Paediatric Society Fetus and Newborn Committee, Batton DG, Barrington KJ, Wallman C. Prevention and management of pain in the neonate: an update. Pediatrics 2006;118(5):2231-2241. 